\title{
Bioactive Glasses at the Atomic Scale: the Complementary use of Advanced Probe and Computer Modelling Methods.
}

Jamieson K. Christie ${ }^{a}$, Alastair N. Cormack ${ }^{b}$, J ohn V. Hanna ${ }^{c}$, Richard A. Martin ${ }^{d}$, Robert J . Newport ${ }^{d, 1}$, David M. Pickup ${ }^{d}$ and Mark E. Smith ${ }^{c}$

a) Department of Chemistry, University College London, WCIH OAJ, UK. ${ }^{2}$

b) Inamori School of Engineering, Alfred University, NY 14802, USA.

c) Department of Physics, University of Warwick, Coventry, CV4 7AL, UK. ${ }^{3}$

d) School of Physical Sciences, University of Kent, Canterbury, CT2 7NH, UK. ${ }^{4}$

\begin{abstract}
Sol-gel synthesised bioactive glasses may be formed via a hydrolysis condensation reaction, silica being introduced in the form of tetraethyl orthosilicate (TEOS) and calcium is typically added in the form of calcium nitrate. The synthesis reaction proceeds in an aqueous environment; the resultant gel is dried, before stabilisation by heat treatment. These materials, being amorphous, are complex at the level of their atomic-scale structure, but their bulk properties may only be properly understood on the basis of that structural insight. Thus, a full understanding of their structure : property relationship may only be achieved through the application of a coherent suite of leading-edge experimental probes, coupled with the cogent use of advanced computer simulation methods. Using as an exemplar a calcia-silica sol-gel glass of the kind developed by Larry Hench, to whose memory this paper is dedicated, we illustrate the successful use of high-energy $x$-ray and neutron scattering

\footnotetext{
${ }^{1}$ Corresponding author: r.j.newport@kent.ac.uk

${ }^{2}$ Present address: Department of Materials, Loughborough University, LE11 3TU, UK.

${ }^{3}$ Mark Smith's present address: Vice-Chancellor's Office, Lancaster University, LA1 4YW, UK.

${ }^{4}$ Richard Martin's present address: Engineering \& Applied Science, Aston University, Birmingham, B4 7ET, UK.
} 
(diffraction) methods, magic-angle spinning solid state NMR, and molecular dynamics simulation as components to a powerful methodology for the study of amorphous materials.

\section{I ntroduction}

Obtaining information on the positions of atoms within the regular array that is a crystal is well understood - take away that sample-wide order and one faces a more challenging problem altogether. Given an amorphous solid, e.g. a glass, which possesses no order to the arrangement of their atoms beyond that driven by short-range chemical/electrostatic forces (i.e. over a distance corresponding to only a few atomic diameters), how does one extract quantitative information about the distribution of atoms of one element with respect to the other elements present? One may illustrate the complexity of this question by considering a 'simple' glass comprising the two elements $\mathrm{Si}$ and $\mathrm{O}$ only. For a full understanding of the atomic-scale structure of the silica glass one needs to know the distribution of $\mathrm{Si}$ atoms around $\mathrm{O}$ (and equivalently, $\mathrm{O}$ around $\mathrm{Si}$ ), $\mathrm{Si}$ atoms around other $\mathrm{Si}$ atoms, and $\mathrm{O}$ around other $\mathrm{O}$ atoms. Thus, from one experiment yielding a single data set the structure factor from diffraction, say - one must attempt to extract three distinct distributions, the partial structure factors: this is, self-evidently, not possible. The complexity of the puzzle increases rapidly if one were to add more elements; in general, there are $1 / 2 \mathrm{~N}(\mathrm{~N}+1)$ partial structure factors for a sample comprising $\mathrm{N}$ elements. Even if one chooses to ignore the residual presence of $\mathrm{H}$ in a sol-gel calcia-silica glass, there would be six partial pairwise correlations to consider. Add to this the fact that the scientifically key pair terms may be associated with an element present at low concentration and the problem becomes even less tractable. However, this intrinsic limitation may be overcome by combining multiple complementary datasets in a coherent manner. We describe herein one such approach, in which advanced neutron and x-ray scattering complements leading-edge solid state NMR, and our interpretation of this experimental data is informed and enhanced through molecular dynamic computer simulation. 


\section{Neutron and x-ray diffraction}

Synchrotron-based high-energy $x$-ray diffraction (HEXRD) and neutron diffraction (ND) are powerful techniques that can be used to probe the structure of amorphous materials such as sol-gel glasses. This may include key stages of materials processing as well as providing insights into the glass' final state [1, 2]. Conventional HEXRD and ND experiments on amorphous materials yield a real-space pair-distribution function (PDF) which contains a series of peaks that correspond to the correlations between pairs of atoms. The PDF can be simulated to obtain structural parameters such as interatomic distances, coordination numbers and disorder parameters. The major limitation of this method is the difficulty of obtaining information on individual correlations from a single PDF where the correlations overlap. For example, in the PDF from bioactive $(\mathrm{CaO})_{0.3}\left(\mathrm{SiO}_{2}\right)_{0.7}$ sol-gel glass the $\mathrm{Ca}-\mathrm{O}$ correlation appears as a broad feature at around $2.35 \AA$ that overlaps with the strong O(Si)-O correlation at $2.64 \AA$; this makes a quantitative determination of the Ca environment impossible $[3,4]$. The case of $(\mathrm{CaO})_{0.3}\left(\mathrm{SiO}_{2}\right)_{0.7}$ sol-gel glass is further complicated by the fact that calcium often adopts complex local environments in silicates, as evidenced by the diverse calcium environment in crystalline calcium silicate minerals [5].

The approach adopted by Skipper et al. to circumvent the problems described above was to use neutron diffraction with isotopic substitution (NDIS) in order to extract the atomic correlations involving calcium [4]. This technique makes use of the fact there are stable isotopes of calcium with different neutron scattering lengths. By preparing two samples that are identical except for the isotope of calcium they contain, and taking a difference between the measured ND datasets, a PDF can be obtained that contains only the correlations that involve calcium (all other pairwise correlations being identical in the datasets collected from the two samples). 
Two $(\mathrm{CaO})_{0.3}\left(\mathrm{SiO}_{2}\right)_{0.7}$ samples were prepared by the sol-gel method [6]: one containing natural calcium ( ${ }^{\text {nat }} \mathrm{Ca}$ ) which has an average coherent scattering length of $4.70 \mathrm{fm}$ and one containing calcium enriched with ${ }^{44} \mathrm{Ca}$, scattering length $1.42 \mathrm{fm}$. HEXRD data confirmed the samples to be structurally equivalent. The ND data were collected on the GEM diffractometer on the ISIS Spallation Neutron Source, UK. The resultant PDFs are shown in Figure 1.

(a)

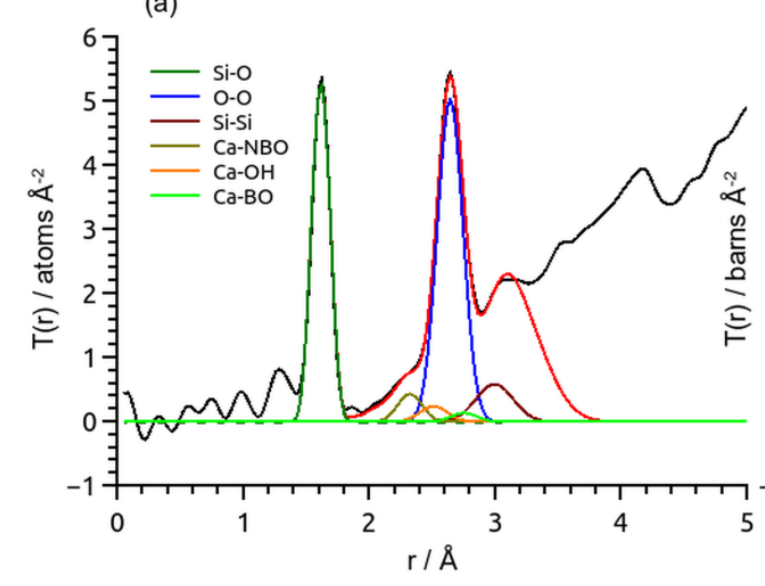

(b)

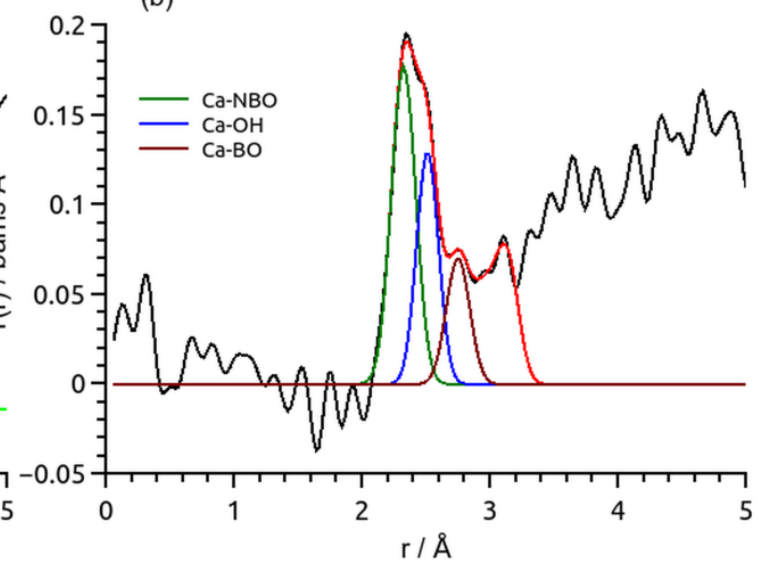

Figure 1. Neutron PDFs from $(\mathrm{CaO})_{0.3}\left(\mathrm{SiO}_{2}\right)_{0.7}$ (black lines) and their simulations (red lines) showing key correlations: (a) PDF from $\left({ }^{44} \mathrm{CaO}\right)_{0.3}\left(\mathrm{SiO}_{2}\right)_{0.7}$ and (b) ${ }^{\text {nat }} \mathrm{Ca}-{ }^{44} \mathrm{Ca}$ difference PDF with non-Ca correlations eliminated [nx4]. The fits and partial correlation functions were generated using NXFit [nx7].

Analysis of the neutron PDFs from the two samples revealed that sol-gel $(\mathrm{CaO})_{0.3}\left(\mathrm{SiO}_{2}\right)_{0.7}$ has a structure based on an incomplete network of $\mathrm{SiO}_{4}$ tetrahedra with non-bridging oxygen atoms (NBOs, i.e. those not providing a bonded link between network Si atoms) terminated by protons and $\mathrm{Ca}^{2+}$ ions. The results of fitting the NDIS PDF showed that the calcium environment consists of three partially overlapping $\mathrm{Ca}-\mathrm{O}$ correlations with 
resolvable distances of $2.3,2.5$ and $2.75 \AA$. On the basis of molecular dynamics simulations, Mountjoy and Mead assigned these correlations to $\mathrm{Ca}-\mathrm{NBO}, \mathrm{Ca}-\mathrm{OH}$ and $\mathrm{Ca}-\mathrm{BO}(\mathrm{BO}=$ bridging oxygen), respectively [8]. The $\mathrm{Ca}-\mathrm{NBO}$ and $\mathrm{Ca}-\mathrm{BO}$ correlations have since been confirmed in the melt quench $45 S 5$ analogue at $\sim 2.33$ and $2.75 \AA$ using diffraction and computer modelling; as anticipated, the $\mathrm{Ca}-\mathrm{OH}$ is absent in the melt quench derived sample [9]. The complex $\mathrm{Ca}-\mathrm{O}$ environment provided the first clue towards explaining why calcium loss from sol-gel $(\mathrm{CaO})_{0.3}\left(\mathrm{SiO}_{2}\right)_{0.7}$ occurs readily by simple ion exchange with body fluid.

Skipper et al. have shown that calcium is not incorporated into the silica network until the glassy material is heated to $\sim 400{ }^{\circ} \mathrm{C}$, at which point the nitrate breaks down and $\mathrm{Ca}$ enters the network [1]. Additionally, the NDIS study described above was extended by soaking the heat-treated final materials in simulated body fluid (SBF) for 30 minutes and repeating the NDIS experiments [10]. The results revealed that calcium associated with non-bridging oxygens was preferentially leached into the SBF. The reduction in intensity of the peak at $2.3 \AA$ in the first order difference function PDF was accompanied by a domination of the feature at $2.5 \AA$ by the peak at $2.7 \AA$. These changes were interpreted as the formation of calcium phosphates after immersion in SBF, since the $\mathrm{Ca}-\mathrm{O}$ distances are longer in calcium phosphates [11]. FitzGerald et al. undertook a complementary in situ and time-resolved HEXRD study of bioactive sol-gel $(\mathrm{CaO})_{0.3}\left(\mathrm{SiO}_{2}\right)_{0.7}$ foam immersed in SBF on beamline ID15 at the ESRF, France [3]. The results showed that after $\sim 1$ hour of exposure to SBF, weak Bragg peaks could be observed, after $\sim 3$ hours a layer of tricalcium phosphate and hydroxyapatite was evident and after $\sim 5$ hours the formation of hydroxycarbonate apatite was observed. Again, evidence of preferential dissolution of calcium from the Ca-NBO environment was observed. Furthermore, changes to the $\mathrm{O}-(\mathrm{Si})-\mathrm{O}$ correlation associated with $\mathrm{SiO}_{4}$ groups provided direct evidence of disruption to the underlying glass network as the reaction proceeded. 


\section{Solid State NMR}

Solid state NMR provides information about the details of local atomic scale structure of a material, extending up to a few atomic neighbours away from the target atom's position. A fully multinuclear approach means that a perspective is provided from each different nucleus [12]. In recent years, the increasing availability of first principles quantum calculations of the NMR parameters strongly complements the NMR data by revealing the intricacies of the atomic scale structure [13, 14], which for bioactive glasses directly influences their osteogenic properties.

For the $(\mathrm{CaO})_{0.3}\left(\mathrm{SiO}_{2}\right)_{0.7}$ sol-gel glass considered here the three nuclei $\left({ }^{17} \mathrm{O},{ }^{29} \mathrm{Si},{ }^{43} \mathrm{Ca}\right)$ can all be observed by NMR with varying degrees of difficulty. ${ }^{1} \mathrm{H}$ NMR has provided direct evidence about the proton content in the porous structure, and on reaction with SBF ${ }^{31} \mathrm{P}$ NMR indicates how the phosphate phases develop over time. The differently connected $\mathrm{SiO}_{4}$ species - $\mathrm{Q}^{0}$ to $\mathrm{Q}^{4}$ - can usually be readily distinguished from their differing chemical shifts within the resolution of the magic angle spinning (MAS) ${ }^{29} \mathrm{Si}$ spectra, even for amorphous solids [12]. The network's average connectivity $\left(D_{c}\right)$ is summarised as the sum of ( $n \times$ (fraction $\left.Q^{n}\right)$ ). $\mathrm{Ca}\left(\mathrm{NO}_{3}\right)_{2}$ is a common Ca source in sol-gel formed bioactive $(\mathrm{CaO})_{0.3}\left(\mathrm{SiO}_{2}\right)_{0.7}$ and $D_{c}$ initially increases and was much higher than the composition predicted. Extensive study and cross referencing the different characterisation techniques showed very clearly that the 5-8 $\mathrm{nm}$ secondary silicate particles have $\mathrm{Ca}^{2+}$ and $\mathrm{NO}_{3}{ }^{-}$interacting with the surface, such that the Ca is not yet playing a direct role in the silicate network [15]. On stabilisation at $600^{\circ} \mathrm{C}$ the nitrate has thermally decomposed and the Ca directly interacts with the silicate to satisfy its charge-balance needs by creating non-bridging oxygens and decreasing the network connectivity; this is confirmed by ${ }^{29}$ Si MAS NMR data [15]. 
Although $\mathrm{Ca}\left(\mathrm{NO}_{3}\right)_{2}$ has many advantages, the high stabilisation temperature required to decompose the nitrate makes it unsuitable for producing hybrids as these temperatures destroy the polymer component. In making a detailed comparison of $\mathrm{Ca}\left(\mathrm{NO}_{3}\right)_{2}, \mathrm{CaCl}_{2}$ and $\mathrm{Ca}\left(\mathrm{OCH}_{2} \mathrm{CH}_{2} \mathrm{OCH}_{3}\right)_{2}$ as calcium sources ${ }^{29} \mathrm{Si} \mathrm{NMR}$ gave $\mathrm{D}_{\mathrm{c}}$ for initially aged samples of 3.65 , $3.55,2.17$ and those stabilised at $700^{\circ} \mathrm{C}$ of $3.28,3.75$ and 3.14 for the three calcium sources respectively [16]. The data clearly show that $\mathrm{CaCl}_{2}$ is completely unsuitable as the Ca appears to interact very little with the silicate network at any temperature. However, the low $D_{c}$ in the initial gel for $\mathrm{Ca}\left(\mathrm{OCH}_{2} \mathrm{CH}_{2} \mathrm{OCH}_{3}\right)_{2}$ indicates that $\mathrm{Ca}$ is already strongly interacting with the network, making it highly suitable for low temperature processing schemes. In gels, network connectivity can be reduced via both conventional chargebalancing oxygens (i.e. $\mathrm{Si}-\mathrm{O}^{-}$) and $\mathrm{Si}-\mathrm{OH}$. As protons are relatively dilute in these systems modest MAS can produce ${ }^{1} \mathrm{H}$ NMR spectra from which both the identity and amount of proton species can be determined [17]. For monoliths produced from $\mathrm{Ca}\left(\mathrm{NO}_{3}\right)_{2}$ optical microscopy clearly revealed two distinct macroscopic regions [18]. A combination of ${ }^{1} \mathrm{H}$ and ${ }^{29} \mathrm{Si}$ NMR was able to show that both the proton content (by a factor 3 ) and the connectivity of the silicate framework (by $3 \%$ ) were higher in the inner region, consistent with lower $\mathrm{Ca}$ content.

${ }^{17} \mathrm{O}$ has much potential as a direct observer of the framework species, with a relatively large chemical shift range and usually modest quadrupolar interaction. The low natural abundance $(0.017 \%)$ necessitates isotopic enrichment, but this is relatively straightforward in a sol-gel produced sample. The distinction between bridging $\mathrm{O}(\mathrm{BO})$ and non-bridging $\mathrm{O}(\mathrm{NBO})$ for calcium silicates is straightforward even in direct MAS spectra. It is clear from Fig. 2(a) that in a sample heated to $120^{\circ} \mathrm{C}$ there is no NBO peak at $100 \mathrm{ppm}$. However, on increasing the heat treatment temperature to 500 then $700^{\circ} \mathrm{C}$ the NBO peak can be seen progressively to increase in intensity as the calcium creates additional NBO [19]. 

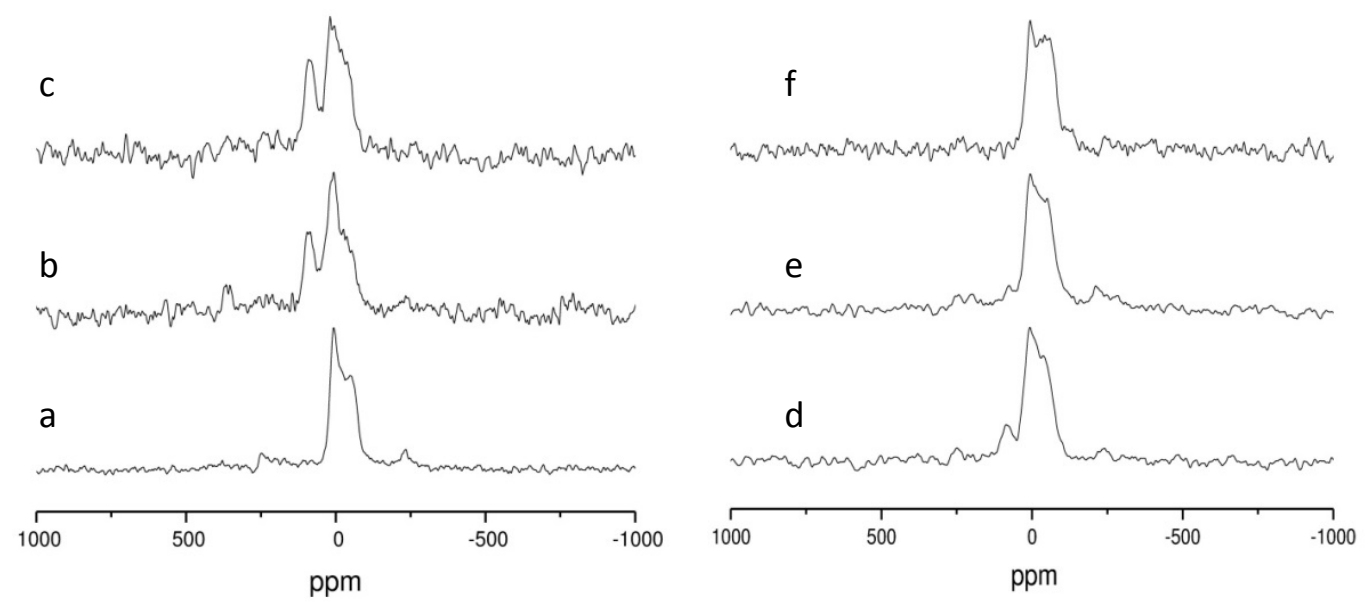

Figure 2. ${ }^{17} \mathrm{O}$ MAS NMR data collected at $14.1 \mathrm{~T}$ of $(\mathrm{CaO})_{0.3}\left(\mathrm{SiO}_{2}\right)_{0.7}$ heated to (a) 120 , (b) 500 and (c) $700^{\circ} \mathrm{C}$, and of $(\mathrm{CaO})_{0.2}\left(\mathrm{SiO}_{2}\right)_{0.8}$ (d) before and after (e) 1 hour and 24 hours reaction with SBF (adapted from [NMR8]).

${ }^{43} \mathrm{Ca}$ is a more difficult nucleus for NMR due to its small magnetic moment, low natural abundance and quadrupolar nature [12]. However natural abundance studies at high field are often sufficient to produce interesting information. ${ }^{43} \mathrm{Ca}$ NMR directly confirmed that at temperatures $\leq 350^{\circ} \mathrm{C}$, although no $x$-ray diffraction peaks of $\mathrm{Ca}\left(\mathrm{NO}_{3}\right)_{2}$ could be detected, the ${ }^{43} \mathrm{Ca}$ resonance was very similar to bulk $\mathrm{Ca}\left(\mathrm{NO}_{3}\right)_{2}$ indicating that very highly dispersed calcium nitrate is present. After higher temperature heat treatment the ${ }^{43} \mathrm{Ca} N M R$ signal is lost due to the chemical shift dispersion present as calcium has a wide range of local environments in the stabilised gel. This makes an interesting comparison with the meltquench analogue where a strong signal is observed in the glass [9]. Inversion of ${ }^{43} \mathrm{Ca}$ 3QMAS NMR data [9] could be rationalised with two signals: a Ca largely coordinated with BO and the other largely associated with NBO [20]. This data provided good corroboration of the ND data by cross-referencing the various Ca correlations.

The ultimate utility of these calcium silicates depends on their bioactivity, which may be studied via subsequent reaction with SBF. The release of $\mathrm{Ca}^{2+}$ (and silicate) ions into the 
solution is an important trigger event for subsequent cell development. ${ }^{17} \mathrm{O}$ MAS NMR shows that, on contact with SBF, the NBOs associated with Ca are rapidly lost (Fig. 2). It appears that there is a rapid exchange between $\mathrm{Ca}^{2+}$ ions and $\mathrm{H}^{+}$such that calcium is released and the surface rapidly becomes hydroxylated [19]. During this process $D_{c}$ drops slightly. This then creates favourable conditions for the surface deposition of calcium phosphates on the way to hydroxycarbonate apatite (HCA). The spin- $1 / 2{ }^{31} \mathrm{P}$ is an ideal probe nucleus with high intrinsic signal sensitivity and a highly dispersed chemical shift range for detection of different phosphate environments. The ${ }^{31} \mathrm{P}$ NMR data shows that a phosphate phase forms very rapidly (within a few minutes) and that, from a relatively early stage, its chemical shift closely resembles quite well ordered HCA [19].

\section{Molecular Dynamics simulation}

Molecular dynamics (MD) simulation is a powerful computational method for probing a material's structure and properties. It is conceptually simple: for each timestep, starting from the atomic positions, the interatomic forces are modelled via Newton's Law $\mathbf{F}=$ ma, and the atoms are then moved to new positions under those accelerations; these positions are used in the next timestep. The interatomic forces can be modelled either quantummechanically or with an empirical classical approximation. Because MD provides the atomic positions throughout the trajectory, it can be used to extract information about structure and properties at local and larger length scales, providing an effective complement to experimental techniques.

The standard method for preparing a glass in the computer is to create an equilibrated melt (or liquid) whose temperature is then reduced to body or room temperature [21], forming a disordered solid. Bioactive glasses such as 4555 Bioglass ${ }^{\circledR}$ and related phosphosilicate glasses have been modelled in this way $[22,23]$. Further simulations have extended this 
basic composition space by substituting $\mathrm{Sr}$ for $\mathrm{Ca}$ [24] and introducing fluorine [25, 26]. Characterisation of these simulated structures show that the network connectivity parameter introduced by Hill [27], whilst being a useful guideline, does not reflect the full range of topological structure in these glasses. This is embodied in the $\mathrm{Q}^{\mathrm{n}}$ distribution, for example, or in the greater extent of network fragmentation displayed by the more bioactive glasses and the concomitant spatial distribution of the modifiers in these glasses (which, of course, determines the $\mathrm{Q}^{\mathrm{n}}$ distribution).

For applications in tissue engineering, low-temperature sol-gel preparative routes are often used. Glasses formed in this way still retain a number of $-\mathrm{OH}$ groups which leads to more open, lower-density glasses. The most common composition of sol-gel derived bioactive glasses is $(\mathrm{CaO})_{0.3}\left(\mathrm{SiO}_{2}\right)_{0.7}$, as investigated by Mead and Mountjoy [8]. Their structures contained hydroxyl species not bonded to $\mathrm{SiO}_{4}$ tetrahedra, but which were preferentially coordinated to the network modifying $\mathrm{Ca}$ ions. These 'free'- $\mathrm{OH}$ come from the dissociation of added $\mathrm{H}_{2} \mathrm{O}$ molecules. Likewise, a quantum-mechanical study of water in Bioglass [28] also contained free $-\mathrm{OH}$, which arose from the dissociation of water molecules. A similar observation was made by Tilocca [29] on a $45 \mathrm{~S} 5$ glass in which a quantity of $\mathrm{Na}$ were replaced by protons.

The presence of modifiers, such as calcium and protons (as hydroxyl ions), in the glass structure should, in principle, reduce its network connectivity and enhance bioactivity. However, as just noted, a significant fraction of the hydroxyl oxygen atoms bond directly to the (sodium and) calcium, and not to silicon. In this case, the effect on the glass structure is to increase the silicate network connectivity above that which might be expected [8, 28], as also found in more complicated hydrated yttrium aluminosilicate glasses [3]. Clustering of modifier cations is also potentially important because it increases bioactivity [31], and these distributions of modifier cations are readily addressed by MD simulations [32]. For 
$(\mathrm{CaO})_{0.3}\left(\mathrm{SiO}_{2}\right)_{0.7}$, some slight clustering is observed: the $\mathrm{Ca}-\mathrm{Ca}$ coordination number is slightly larger than would be expected if $\mathrm{Ca}$ were randomly distributed. The amount of $\mathrm{Ca}$ clustering appears to increase with decreasing Ca content, as has been found for modifier ions in melt-quenched yttrium aluminosilicate glasses [31].

Although there has been no simulation of $(\mathrm{CaO})_{0.3}\left(\mathrm{SiO}_{2}\right)_{0.7}$ interacting with the body, simulations of other bioactive glass compositions provide some insight. These bioactive glass compositions contain both sodium and calcium as network modifiers, so the structures are not exactly comparable, although there are many similarities. The glass surface is first enriched with sodium, which interacts with water outside the glass, allowing water to enter the glass itself, which begins the dissolution [8]. For these glasses, Ca-water interactions occur after $\mathrm{Na}$ has been leached into the solution; for the $\mathrm{Na}$-free $(\mathrm{CaO})_{0.3}\left(\mathrm{SiO}_{2}\right)_{0.7}$ composition, the Ca-water interactions will presumably occur first, although more slowly as $\mathrm{Ca}$ is less mobile through the glass structure than $\mathrm{Na}$ [28]. Ca also binds to hydroxyl groups created by water dissociation, stabilising this process [28]. One might speculate that the migration of the Ca cation in such cases (e.g. surface gel layers) is a co-operative process involving the hydrating $-\mathrm{OH}$ species as well as the Ca cation itself. Amongst the most reactive sites on the glass surface are non-bridging oxygen atoms (often associated with modifier cations) $[28,33,34]$; these can promote water dissociation and the formation of silanol Si-O-H groups on the surface of the glass, which is one of the early steps in the bioactive glass dissolution process. In addition, a large number of the free hydroxyl groups introduced into the glass structure are bound to the modifier cations [29], as also observed in $(\mathrm{CaO})_{0.3}\left(\mathrm{SiO}_{2}\right)_{0.7}$.

\section{Conclusions}

We have demonstrated the efficacy of using complementary experimental structural probes

- in this case, neutron and high-energy x-ray diffraction alongside solid state NMR - as a 
suitable methodological approach to the problem of determining the details of the atomicscale structure of amorphous materials. Moreover, we have also shown that MD simulations, whether classical or quantum mechanical, provide information about the structure and structure-related properties, such as reactivity, which both complement and supplement experimental data. Because they offer "direct" atomic scale pictures of the structure, the simulations are valuable aids to the interpretation of that experimental data.

\section{Acknowledgements}

We thank our respective institutions for their support; the work undertaken in the UK was funded via EPSRC and STFC awards.

\section{References}

[1] L.J. Skipper, F.E. Sowrey and R.J. Newport, Z. Lin and M.E. Smith; “X-ray and neutron diffraction and solid state NMR studies of the growth of hydroxyapatite on bioactive calciasilica sol-gel glasses." Phys \& Chem Glasses 46, 372 (2005).

[2] R.J. Newport, L.J. Skipper, D. Carta, D.M. Pickup, F.E. Sowrey, M.E. Smith, P. Saravanapavan and L.L. Hench; "The use of advanced diffraction methods in the study of the structure of a bioactive calcia:silica sol-gel glass." J Mater. Sci.-Mater. M. 17, 1003 (2006).

[3] V. FitzGerald, K.O. Drake, J.R. Jones, M.E. Smith, V. Honkimäki, T. Buslaps, M. Kretzschmer, R.J. Newport; “In situ high-energy X-ray diffraction study of a bioactive calcium silicate foam immersed in simulated body fluid." J. Synchrotron Radiat. 14, 492-499 (2007).

[4] L.J. Skipper , F.E. Sowrey, D.M. Pickup, K.O. Drake, M.E. Smith, P. Saravanapavan, L.L. Hench and R.J. Newport; "The structure of a bioactive calcia-silica sol-gel glass." J. Mater. Chem. 15, 2369-2374 (2005). 
[5] F.E. Sowrey, L.J. Skipper, D.M. Pickup, K.O. Drake, Z. Lin, M.E. Smith and R.J . Newport; “Systematic empirical analysis of calcium-oxygen coordination environment by calcium Kedge XANES." Phys. Chem. Chem. Phys. 6, 188 (2004).

[6] P. Saravanapavan and L. L. Hench; “Mesoporous calcium silicate glasses: I. Synthesis.” J. Non-Cryst. Solids 318, 1-13 (2003).

[7] D.M. Pickup, R.M. Moss and R.J. Newport; “NXFit: a program for simultaneously fitting x-ray and neutron diffraction pair-distribution functions to provide optimized structural parameters." J. Appl. Cryst. 47, 1790-1796 (2014).

[8] R.N. Mead and G. Mountjoy; "Modeling the local atomic structure of bioactive sol-gelderived calcium silicates." Chem. Mater. 18(17), 3956-3964 (2006).

[9] R.A. Martin, H.L. Twyman, G.J. Rees, E.R. Barney, R.M. Moss, J.M. Smith, R.G. Hill, G. Cibin, T. Charpentier, M.E. Smith, J.V. Hanna, R.J. Newport; “An examination of the calcium and strontium site distribution in bioactive glasses through isomorphic neutron diffraction, X-ray diffraction, EXAFS and multinuclear solid state NMR." J. Mater. Chem. 22, 22212 (2012).

[10] R.J. Newport, L.J. Skipper, V. FitzGerald, D.M. Pickup, M.E. Smith, J.R. Jones; “In vitro changes in the structure of a bioactive calcia-silica sol-gel glass explored using isotopic substitution in neutron diffraction." J. Non-Cryst. Solids 353, 1854-1859 (2007).

[11] D.A. Fletcher, R.F. McMeeking and D. Parkin; The United Kingdom Chemical Database Service; J. Chem. Inf. Comp. Sci. 13, 746-749 (1996).

[12] K.J.D. MacKenzie and M.E. Smith; Multinuclear Solid State NMR of Inorganic Materials, Pergamon Press, UK, (2002).

[13] T. Charpentier; “The PAW/GIPAW approach for computing NMR parameters: A new dimension added to NMR study of solids", Solid State Nucl. Magn. Reson., 40, 1-20, (2011). [14] C. Bonhomme, C. Gervais, F. Babonneau, C. Coelho, F. Pourpoint, T. Azais, S.E. Ashbrook, J.M. Griffin, J.R. Yates, F. Mauri and C.J. Pickard; “First-principles calculation of 
NMR parameters using the gauge including projector augmented wave method: A chemist's point of view", Chem Rev., 112, 5733-5779, (2012).

[15] S. Lin, C. Ionescu, K.J. Pike, M.E. Smith and J.R. Jones; “Nanostructure evolution and calcium distribution in sol-gel derived bioactive glass", J. Mater. Chem., 19, 1276-1282, (2009).

[16] B. Yu, C.A. Turdean-Ionescu, R.A. Martin, R.J. Newport, J.V. Hanna, M.E. Smith and J.R. Jones; "Effect of calcium source on structure and properties of sol-gel derived bioactive glasses", Langmuir, 28, 17465-11476, (2012).

[17] J.R. Jones, T.F. Kemp and M.E. Smith; "Effect of $\mathrm{OH}$ content on the bioactivity of solgel derived glass foam scaffolds", Key Engin. Mater., 309-311, 1031-1034, (2006).

[18] S. Lin, C. Ionescu, S. Baker, M.E. Smith and J.R. Jones; "Characterisation of the inhomogeneity of sol-gel-derived $\mathrm{SiO}_{2}-\mathrm{CaO}$ bioactive glass and a strategy for its improvement", J. Sol-Gel Sci. Technol., 53, 255-262, (2010).

[19] Z. Lin, J.R. Jones, J.V. Hanna and M.E. Smith; "A multinuclear solid state NMR spectroscopic study of the structural evolution of disordered calcium silicate sol-gel biomaterials", Phys. Chem. Chem. Phys., 17, 2540-2549, (2015).

[20] Z. Lin, M.E. Smith, F.E. Sowrey and R.J. Newport; "Probing the local structural environment of calcium by natural-abundance solid-state ${ }^{43} \mathrm{Ca} N M \mathrm{~N}^{\prime \prime}$, Phys. Rev. B, 69, 224107(7), (2004).

[21] K. Vollmayr, W. Kob and K. Binder; "Cooling rate effects in amorphous silica: a computer simulation", Phys. Rev. B 54, 15808-27 (1996).

[22] A. Tilocca, N. H. de Leeuw and A. N. Cormack; "Shell-model molecular dynamics calculations of modified silicate glasses", Phys. Rev. B 73, 104209 (2006).

[23] A. Tilocca, A. N. Cormack and N. H. de Leeuw; "The structure of bioactive silicate glasses: new insight from molecular dynamics simulations", Chem. Mater. 19, 95-103 (2007). 
[24] Y. Xiang and J. Du; “Effect of strontium substitution on the structure of 4555 bioglasses", Chem. Mater. 23, 2703-17 (2011).

[25] G. Lusvardi, G. Malavasi, M. Cortada, L. Menabue, M. C. Menziani, A. Pedone and U. Segre; "Elucidation of the structural role of fluorine in potentially bioactive glasses by experimental and computational investigation", J. Phys. Chem. B 112, 12730-39 (2008)

[26] J. K. Christie, A. Pedone, M. C. Menziani and A. Tilocca; "Fluorine environment in bioactive glasses: ab initio molecular dynamics simulations", J. Phys. Chem. B 115, 203845 (2011).

[27] R.G. Hill, "An alternative view of the degradation of Bioglass"; J. Mater. Sci. Lett. 15, 1122-25 (1996).

[28] E. Berardo, M. Corno, A. N. Cormack, P. Ugliengo and A. Tilocca; “Probing the fate of interstitial water in bulk bioactive glass by ab initio simulations", RSC Adv. 4, 36425-36 (2014).

[29] A. Tilocca; "Atomic-scale models of early-stage alkali depletion and $\mathrm{SiO}_{2}$-rich gel formation in bioactive glasses", Phys. Chem. Chem. Phys. 17, 2696-2702 (2015).

[30] J. Malik and A. Tilocca; "Hydration effects on the structural and vibrational properties of yttrium aluminosilicate glasses for in situ radiotherapy", J. Phys. Chem. B 117, 14518-28 (2013).

[31] J. K. Christie and A. Tilocca; "Aluminosilicate glasses as yttrium vectors for in situ radiotherapy: understanding composition-durability effects through molecular dynamics simulations", Chem. Mater. 22, 3725-34 (2010).

[32] A. Tilocca and A. N. Cormack; "Structural effects of phosphorus inclusion in bioactive silicate glasses", J. Phys. Chem. B, 111, 14256-14264 (2007).

[33] J. Du and A. N. Cormack; "Molecular dynamics simulations of the structure and hydroxylation of silica glass surfaces", J. Amer. Ceram. Soc. 88, 2352 (2005).

[34] A. Tilocca and A. N. Cormack; "Modelling the water-Bioglass Interface by ab initio molecular dynamics simulations", ACS App. Mat. \& Inter. 1, 1324-33 (2009). 


\section{Figure captions}

Figure 1. Neutron PDFs from $(\mathrm{CaO})_{0.3}\left(\mathrm{SiO}_{2}\right)_{0.7}$ (black lines) and their simulations (red lines) showing key correlations: (a) PDF from $\left({ }^{44} \mathrm{CaO}\right)_{0.3}\left(\mathrm{SiO}_{2}\right)_{0.7}$ and (b) ${ }^{\text {nat }} \mathrm{Ca}-{ }^{44} \mathrm{Ca}$ difference PDF with non-Ca correlations eliminated [4]. The fits and partial correlation functions were generated using NXFit [7].

Figure 2. ${ }^{17} \mathrm{O}$ MAS NMR data collected at $14.1 \mathrm{~T}$ of $(\mathrm{CaO})_{0.3}\left(\mathrm{SiO}_{2}\right)_{0.7}$ heated to (a) 120 , (b) 500 and $(\mathrm{c}) 700^{\circ} \mathrm{C}$, and of $(\mathrm{CaO})_{0.2}\left(\mathrm{SiO}_{2}\right)_{0.8}$ (d) before and after (e) 1 hour and 24 hours reaction with SBF (adapted from [19]). 